\title{
¿QUÉ ES HUMANO? TABÚS ALIMENTARIOS Y ANTROPOFAGIA EN EL NOROESTE DE MOZAMBIQUE ${ }^{1}$
}

\author{
ARIANNA HUHN \\ California State University
}

\section{Introducción}

El epíteto "caníbal” es un tropo empleado en todo el mundo, a menudo para ensombrecer la humanidad de vecinos detestados o misteriosos habitantes de tierras lejanas. Un ejemplo muy conocido es el de los exploradores y colonialistas europeos de los siglos XVIII y XIX que describieron, generalmente de oídas, como comedores de hombres a pueblos encontrados a lo largo del mundo. Las connotaciones de primitivismo, brutalidad y violencia estimularon el ímpetu del norte global por expoliar, someter y "civilizar" al sur global. ${ }^{2}$ Pero las acusaciones de consumo de carne humana también fueron lanzadas en dirección opuesta. Muchos académicos documentan el miedo de los africanos a los europeos que se alimentaban de carne y sangre humana, lo que algunos interpretan como una angustia engendrada por la comercialización de cuerpos humanos africanos en el tráfico transatlántico de esclavos; otros lo explican como el miedo fundado en la incomprensión de sucesos históricos rea-

Este artículo fue recibido por la dirección de la revista el 8 de abril de 2013 y aceptado para su publicación el 19 de julio de 2013.

${ }^{1}$ Esta investigación fue posible por el generoso apoyo financiero de la beca doctoral Fulbright-Hays, y el Departamento de Antropología y la Rectoría de la Universidad de Boston. Deseo agradecer también a Parker Shipton, Joanna Davidson, Michael D. Jackson, Adam Kuper, Shelby Carpenter y Laura Ann Twagira, sus constructivos comentarios a versiones anteriores del material aquí presentado.

${ }^{2}$ Paul Fieldhouse, Food and Nutrition: Custom and Culture, Nueva York, Chapman and Hall, 1995. 
les. ${ }^{3}$ Los africanos también se han acusado de caníbales entre ellos, normalmente como metáfora de depredador. ${ }^{4}$ Los rumores reforzaron el miedo y las acusaciones europeas sobre el continente negro en la era colonial.

Este artículo aborda el uso y la abstención del canibalismo como prácticas que fincan diferencias y sentidos de pertenencia en África al sur del Sahara. Estoy interesada en la creencia de muchas poblaciones africanas de que quienes se entregan a las atroces artes de la hechicería y la brujería también consumen carne humana, así como en las ramificaciones de esta connotación negativa para los tabús alimentarios. Específicamente, ahí donde el consumo de carne humana, como preferencia gustativa, es rasgo distintivo de una casta de individuos cuya orientación antisocial y aislada los hace aparecer como si existieran más allá del reino de la persona humana, quienes desean evitar señalamientos que cuestionen su existencia metafísica deben dejar claro que no están interesados en el consumo de carne humana. Postulo que en Metangula, pueblo nyanja (maravi) del norte de Mozambique, esta situación se ha manifestado en una serie de prohibiciones no sólo del canibalismo (todas las sociedades las tienen), sino también de comer animales semejantes física, emocional y espiritualmente a los humanos; entre ellos, los monos, algunos tipos de pollos, perros, gatos, serpientes, leones, leopardos, hipopótamos y cocodrilos. Mientras los alimentos prohibidos son raramente opciones de consumo, la articulación de tabús y las muestras de repugnancia a la idea de consumirlos son significativas por su contribución a la construcción y realización de los fundamentos morales de la vida social. Lo que propongo, entonces, es que la abstención del canibalismo y el pseudocanibalismo en Metangula no es sólo una declaración simbólica, una preferencia gustativa o una afirmación de benevolencia para contrarrestar ideas europeas falsas. Siguiendo a Alfred Gell, los tabús son algo más

${ }^{3}$ Rosalind Shaw, "The Production of Witchcraft/Witchcraft as Production: Memory, Modernity, and the Slave Trade in Sierra Leone", American Ethnologist, año 24, núm. 4, 1997, pp. 856-876; I. M. Lewis, Religion in Context: Cults and Charisma, Cambridge, Cambridge University Press, 1996.

${ }^{4}$ W. Arens, The Man-Eating Myth: Antbropology \& Antbropophagy, Nueva York, Oxford University Press, 1979. 
que expresiones del yo: también constituyen el yo. ${ }^{5}$ Los tabús alimentarios a que me refiero son formas prácticas reales por las que los individuos devienen socialmente humanos mediante la demostración de su desinterés por conductas y orientaciones asociadas a lo oculto.

$\mathrm{El}$ interés por los tabús alimentarios ha sido constante en los estudios sobre África. Generaciones de investigadores han dejado claro que las prohibiciones de ciertos alimentos, partes de ellos (ciertos cortes de carne) o categorías de alimentos (vegetales de hoja verde) para segmentos de la sociedad (generalmente jóvenes, mujeres o personas en determinadas condiciones, como embarazo, lactancia o luto) son comunes a lo largo del continente. En algunos lugares de África, los tabús alimentarios prohíben el consumo de alimentos totémicos. ${ }^{6} \mathrm{El}$ enfoque académico común incluye las ramificaciones nutricionales o su contribución al control social mediante la reificación de las hegemonías sociales existentes, pero sobre el canibalismo en relación con los tabús alimentarios y la comida ha habido poca atención. Esto no debería sorprender, pues el canibalismo claramente no es un suceso cotidiano y, debido a que lo prohibido no es importante nutricionalmente, ni sociopolíticamente estratificante, su tabú tiene pocas implicaciones prácticas. Además, los encuentros de académicos (y africanos en general) con el canibalismo ocurren por lo regular en el ámbito de la charla más que en actividades directamente observadas, lo que es un terreno académico incómodo.?

No obstante su excepcionalidad, los tabús del canibalismo operan de manera similar a otros tabús alimentarios en África, los cuales son articulados ampliamente como contribuciones prácticas al funcionamiento normal de la sociedad. En otras palabras, ciertos alimentos son prohibidos con la intención de proteger y mantener el decoro propio y asegurar el desarrollo físico y conductual de la persona; por ejemplo, el pescuezo de

${ }^{5}$ Alfred Gell, "Reflections on a Cut Finger: Taboo in the Umeda Conception of the Self", en R. H. Hook (coord.), Fantasy and Symbol: Studies in Anthropological Interpretation, Nueva York, Academic Press, 1979, pp. 133-148.

${ }^{6}$ Fran Osseo-Asare, Food Culture in sub-Saharan Africa, Westport, Greenwood Press, 2005.

${ }^{7}$ Luise White, Speaking with Vampires: Rumor and History in Colonial Africa, Berkeley, University of California Press, 2000. 
las aves de corral puede estar prohibido para las mujeres por su semejanza con el pene. Esto refleja y apoya la formalidad relacionada con la conducta sexual y la seriedad con que se toma la fertilidad. Las restricciones en dietas de lactancia y embarazo son presentadas frecuentemente como preventivas, en este caso para proteger al no nacido de algún sino funesto. En esta perspectiva, los tabús del canibalismo descritos en este artículo están completamente alineados con la estructura y función de otras prohibiciones de alimentos en África, pues la observancia de las reglas es un medio para cimentar la socialidad y la persona.

En lo que resta de este artículo empleo regularmente la palabra "antropofagia" en vez de "canibalismo" al referirme al consumo de humanos o partes de ellos por humanos. Como combinación de palabras griegas (anthropos significa humano y phagein comer), el término técnico "antropofagia” no arrastra la carga ideológica de primitivismo de la palabra más popular de canibalismo. ${ }^{8}$ De ninguna manera pretendo implicar, legitimar o afianzar las descripciones de africanos como personas atrasadas, brutales o de humanidad distinta a la de otros pueblos; de hecho, al prohibir el consumo de carne humana a individuos que representan conductas incivilizadas (hechiceros), los africanos se parecen mucho a otras poblaciones del mundo que emplean la antropofagia para trazar límites culturales y "hacer otro" a quien se desea conquistar, civilizar y difamar. Deseo dejar claro también que, a diferencia de algunos académicos, mi preocupación no es estudiar la práctica real de la antropofagia; enfoco el apetito y el consumo de carne humana como un discurso que es real para gente que lo usa con implicaciones sociales precisas, si bien mundanas. Más aún, deseo aclarar que no creo ni he visto evidencia alguna que sugiera que los africanos son regular o irregularmente caníbales. Empiezo por considerar la antropofagia en relación con los tabús alimentarios, el trazo de límites y la humanización. También detallo la asociación de brujos y hechiceros con la antropofagia en África. Luego discuto el caso específico de Metangula. Una breve conclusión resume los

${ }^{8}$ Shirley Lindenbaum, "Thinking about Cannibalism", Annual Review of Anthropology, año 33, núm. 1, 2004, pp. 475-498. 
argumentos presentados y ubica los hallazgos en las discusiones sobre proscripciones simpatizantes y prohibiciones amplias de cosas consideradas como partes del yo.

\section{Alimentos, demarcación y creación de límites}

Los tabús alimentarios no son exclusivos del continente africano, por supuesto. Todas las poblaciones ponen límites a lo que consideran consumible. Esto puede resultar en "prohibiciones alimenticias" laxas de alimentos específicos para todos o para un grupo de individuos. Los "tabús alimentarios”, en cambio, se refieren a límites más estrictos que probíben el consumo de algunos alimentos con consecuencias sociales y a veces físicas para los transgresores. Si se considera que la mayoría de los alimentos tabú en una sociedad están prohibidos para muchos, surgen las cuestiones de por qué, cuándo, dónde y para quiénes. Los antropólogos y otros académicos ofrecen una gama de explicaciones. Los análisis estructuralistas, por ejemplo, los interpretan como producto de ideologías culturales, las cuales organizan el mundo mediante la asignación de valor a sus elementos físicos y prohíben lo que aparece como anómalo. ${ }^{9} \mathrm{~L}$ as explicaciones materialistas subrayan los resultados prácticos de los tabús, como la conservación del ambiente y la abstención de comer animales utilizados con fines económicos. ${ }^{10}$ Otros sostienen que los sistemas de creencias y rituales simplemente representan poderosos motivos mágico-religiosos para prohibir ciertas comidas. ${ }^{11}$ Cada postura propone orígenes y explicaciones profundamente enraizadas en la cultura.

Independientemente de las posiciones teóricas, es claro que lo que una persona come y no come, y cómo y con quiénes lo hace, refleja lo que esa persona es. En otras palabras, la comida contribuye a la construcción y preservación de identidades,

\footnotetext{
${ }^{9}$ Mary Douglas, Purity and Danger: An Analysis of Concepts of Pollution and Taboo, Nueva York, Praeger, 1966.

${ }^{10}$ Marvin Harris, Good to Eat: Riddles of Food and Culture, Nueva York, Simon and Schuster, 1985.

${ }^{11}$ Frederick J. Simoons, Eat not this Flesh: Food Avoidances from Prehistory to the Present, Madison, University of Wisconsin Press, 1994.
} 
comunica estatus individuales y de grupo, y demarca segmentos sociales por género, etnicidad, edad, clase, etc. Tal capacidad proviene acaso, en parte, de la naturaleza especial de la alimentación. Ya que el alimento se extingue en su consumo, y esto provoca una restitución o recirculación directa, es particularmente apto para cimentar las relaciones sociales. ${ }^{12}$ Las experiencias somáticas relacionadas con alimentos ensanchan la memoria individual de los actos sociales, los cuales pueden ser evocados, en encuentros subsecuentes, asociados a determinados gustos y texturas. ${ }^{13}$ Los orificios corporales por los que los alimentos entran y salen son límites simbólicos sobre los que las preocupaciones sociales suelen implantarse. ${ }^{14} \mathrm{La}$ conexión intercultural entre la comida y el sexo parece privilegiar la alimentación como representación de la reproducción física y social. ${ }^{15}$ Mediante su repetición regulada, los hábitos alimentarios, particularmente los alimentos tabú como demarcadores de límites, ayudan a la cohesión grupal. ${ }^{16}$ En este estudio estoy interesada en la alimentación, específicamente en la antropofagia, no sólo como signo de pertenencia y exclusión, sino también como espacio de acciones racionalizadas e intencionales por las cuales los individuos demuestran su humanidad y así devienen socialmente humanos. En otras palabras, estos tabús no sólo son potentes por su rotunda capacidad de separar grupos (en este caso humanos de no humanos), sino además porque su observancia y contravención expresan cualidades y características que definen a un grupo respecto de otros. En la alimentación, entonces, están implantadas y representadas las afirmaciones locales de humanidad, o persona.

${ }^{12}$ M. Dietler, "Digesting the Feast - Good to eat, Good to drink, Good to think: An Introduction”, en Michael Dietler y Brian Hayden (coords.), Feasts: Archaeological and Ethnographic Perspectives on Food, Politics, and Power, Washington, Smithsonian Institution Press, 2001, pp. 1-22.

${ }^{13}$ E. Sutton, "Food and the Senses", Annual Review of Anthropology, año 39, núm. 1, 2010, pp. 209-223.

${ }^{14}$ Douglas, Purity and Danger, op. cit.

${ }^{15}$ Gillian Feeley-Harnik, "Religion and Food: An Anthropological Perspective", Journal of the American Academy of Religion, año 63, núm. 3, 1995, pp. 565-582.

${ }^{16}$ Ellen Messer, "Food Definitions and Boundaries: Eating Constraints and Human Identities”, en Jeremy MacClancy, C. J. K. Henry y Helen M. Macbeth (coords.), Consuming the Inedible: Neglected Dimensions of Food Choice, Nueva York, Berghahn Books, 2007, pp. 53-66. 
En gran parte de África, las nociones de los modos de vida social correctos e incorrectos están íntimamente entrelazadas con la sociabilidad, la compasión y la circulación. En un sentido amplio, "la persona" no preexiste a su interacción social, sino que es simbólica y literalmente constituida a través de ella. ${ }^{17}$ Es decir, las personas se desarrollan, prosperan y tienen un sentido de bienestar personal dentro de una comunidad, de la que dependen su vida física y su vida espiritual. La convivencia, las relaciones sexuales y otras actividades de interacción sensorial son prácticas comúnmente consideradas como disipadoras de las barreras personales, a través de las cuales pueden emerger otras subjetividades individuadas y continuar los flujos que constituyen y reconstituyen la vida. ${ }^{18}$ No sorprende, por lo tanto, que las conductas que ensanchan y sostienen la interrelación estén entrelazadas y emerjan como creencias y conductas en torno de la producción, distribución, elaboración, consumo y definición de los alimentos. Los etnógrafos han subrayado desde hace tiempo la importancia del intercambio de alimentos en África para establecer, cimentar y perpetuar las relaciones entre vecinos y amigos. Asimismo, los alimentos rara vez son consumidos en soledad o frente a personas hambrientas, en la medida en que comer tiene el propósito, y posiblemente deriva su capacidad, de mantener la existencia en el contexto social del consumo. ${ }^{19}$

La definición de la sociabilidad como principio central de la persona africana no debe ser tomada como afirmación de que tal valoración es exclusiva del continente africano. El sentido de comunidad, en la medida en que es también un sentido del yo personal, es parte de la identidad individual en todo el mundo, indiscutiblemente, si bien cada sociedad balancea ambos sentidos de manera distinta. La afirmación de que las personas sin reciprocidad están incompletas también puede insinuar falsamente la ausencia total de soberanía individual, o la falta

${ }^{17}$ Ivan Karp, "Personhood, Concepts of”, en John Middleton (ed.), Encyclopedia of Africa South of the Sahara, vol. 3, Detroit, Thomson-Gale, 1997, pp. 342-346.

${ }^{18}$ Wenzel Geissler y Ruth Prince, The Land is Dying: Contingency, Creativity and Conflict in Western Kenya, Nueva York, Berghahn Books, 2010.

${ }^{19}$ Arianna Huhn, "The Tongue only works without Worries: Sustenance and Sentiment in a Mozambican Town", Food and Foodways, año 21, núm. 3, 2013, pp. 186-210. 
de animosidad comunitaria y de rivalidades personales, críticas comunes de los escritos africanistas..$^{20} \mathrm{La}$ negociación del balance entre los intereses individuales y los comunitarios, sin embargo, es un motivo de fricción tanto en África como en cualquier otra parte. Mi análisis se basa en la realidad de tal tensión y en un "principio de participación" que guía las decisiones individuales en mi lugar de investigación, como ocurre en toda África. Este principio requiere la priorización activa de la cooperación, la compasión y la abnegación como virtudes morales y como base metafísica de la vida, principios inseparables de la pertenencia a la colectividad, y de los asuntos de la mediación productiva. ${ }^{21}$ Asimismo, mi evaluación de la sociabilidad africana y otros patrones culturales discernibles en el continente no debe ser tomada como afirmación de que las sociedades africanas son homogéneas o indiferenciables. Aunque no hay tal cosa como concepción, creencia o conducta africanas, las notables resonancias justifican ampliamente la tipificación de ciertas características como "africanas". ${ }^{22}$

La domesticación y limitación de la mala voluntad, la ambición, los celos y el deseo de poder son concebidos en gran parte de África, incluido mi lugar de investigación, como opciones activas que definen lo humano. Los africanos a menudo califican a las personas que no aceptan estas restricciones como miembros de lo oculto. Los académicos los llaman "brujos" o "hechiceros", cuya diferencia reside en el origen del maleficio. Si el influjo proviene de cualidades internas, la persona puede ser inconsciente de sus poderes (brujería); si el influjo es producto de encantamientos y objetos, es hechicería. En la práctica muchos africanos no las distinguen, pues ambas están basadas en dañar relaciones humanas para satisfacer apetitos salvajes. En ambos casos, el aislamiento y el egoísmo son concebidos localmente como tendencias naturales, y sus resultados son imagi-

${ }^{20}$ Heinz Kimmerle, "Ubuntu and Communalism in African Philosophy and Art”, en Henk van den Heuvel, Mzamo Mangaliso y Lisa van de Bunt (coords.), Prophecies and Protests: Ubuntu in Glocal Management, Amsterdam, Rozenburg Publishers, 2006, pp. 79-92.

${ }^{21}$ Edward Kanyike, The Principle of Participation in African Cosmology and Anthropology, Balaka, Montfort Media, 2004.

${ }^{22}$ John Comaroff y Jean Comaroff, "On Personhood: An Anthropological Perspective from Africa”, Social Identities, año 7, núm. 2, 2001, pp. 267-283. 
nados como gratificantes, pero también son ruinosos social y cosmológicamente: el desenfrenado autointerés de brujos y hechiceros se manifiesta en excesos, aislamiento y destrucción, que incluyen gula, incesto, ambición e ingesta de carne humana. ${ }^{23}$ La antropofagia es asociada con lo oculto no sólo en África, sino también en muchas poblaciones del mundo $;{ }^{24}$ sin embargo, las cuestiones de quién se come a quién y para qué tienen respuesta en contextos específicos. En África, los brujos y los hechiceros son señalados como engullidores de carne, sangre $\mathrm{u}$ órganos humanos en sus propias comunidades, generalmente de familiares suyos. ${ }^{25}$ Tales actos son concebidos como si tuvieran el efecto de transferir la fuerza vital de la víctima al perpetrador. Entre los académicos hay diferencias de opinión sobre si los africanos consideran que los brujos y los hechiceros ingieren carne humana físicamente, en forma visible y mundana, o si sólo engullen su esencia espiritual. J. W. M. van Breugel escribe que en Malaui, por ejemplo, se supone que hay una ingesta física. ${ }^{26}$ Donde los cuerpos no son comidos, son usados para formular potentes pócimas que traen suerte o riqueza al poseedor. Sean rumores o verdades, estas creencias contribuyen a nutrir el tráfico de órganos humanos reales en Malaui y en toda la región. ${ }^{27}$ Otras poblaciones conciben la antropofagia como acto de consumo astral, donde la víctima no muestra signos visibles de haber sido atacada. Rosalind Shaw, por ejemplo, escribe sobre Sierra Leona, donde los brujos succionan la sangre de la víctima y extirpan su corazón. ${ }^{28}$ La víctima seguirá viviendo pero, como la sangre mantiene su vida y el corazón su voluntad, su cuerpo sólo existirá como un envase de su antiguo yo.

Sea psíquica o física, la antropofagia en África es normalmente concebida como inclemente acumulación de vitalidad

${ }^{23}$ T. O. Beidelman, Moral Imagination in Kaguru Modes of Thought, Washington, Smithsonian Institution Press, 1993.

${ }^{24}$ Neil L. Whitehead y Robin Wright, In Darkness and Secrecy: The Anthropology of Assault Sorcery and Witchcraft in Amazonia, Durham, Duke University Press, 2004.

${ }^{25}$ Arens, The-Man-Eating Myth, op. cit.

${ }^{26}$ J. W. M. van Breugel, Chewa Traditional Religion, Zomba, Kachere Series, 2001.

${ }^{27}$ Colin Murray y Peter Sanders, Medicine Murder in Colonial Lesotho: The Anatomy of a Moral Crisis, Londres, Edinburgh University Press, 2005.

${ }^{28}$ Shaw, "The Production of Witchcraft...", op. cit. 
en beneficio propio, lo que coloca al perpetrador por encima de la comunidad; ésta es precisamente la razón de que la ingesta de carne humana sea apropiadamente atribuida a brujos y hechiceros, quienes anulan la fuerza vital de otros y la acumulan para sí mismos. La expresión estar "consumido en vida” como metáfora de desecación de las capacidades propias, y las conversaciones sobre personas poderosas como "devoradoras" de subordinados, son tan comunes que la frase "política del estómago" ha resultado apta para referirse a la política africana. ${ }^{29} \mathrm{~A}$ menudo se rumora que las élites africanas son cofrades de lo oculto. ${ }^{30}$ Los individuos señalados como sospechosos de hechicería o brujería suelen ser desterrados de la comunidad. Mundanos en la forma, tales actos pueden tener funciones desastrosas. En un contexto donde la vida es vivida a través de las relaciones, la exclusión es parecida a la muerte; en algunos relatos es peor aún, pues los muertos pueden seguir participando en la vida social desde más allá de la tumba. Ser percibido como partícipe de actos ocultos puede resultar también en daño físico. Los reporteros publican historias de todo el continente que describen la muerte de acusados de brujería y hechicería, particularmente mujeres viejas y niños desfavorecidos. No sorprende entonces que los africanos no deseen ser tomados por brujos o hechiceros o volverse uno de ellos, y que el chisme sirva como poderoso mecanismo de control social (como en todo el mundo). En Metangula, sostengo, tales creencias han sido incorporadas a la prohibición de consumir cualquier alimento semejante a la carne humana. Tal es el caso específico al que me referiré a continuación.

\section{Tabús de la carne en Metangula}

Metangula es un pequeño pueblo de aproximadamente 10000 habitantes, localizado sobre la orilla oriental del lago Niassa, o lago Malaui, en la parte más septentrional de Mozambique. Se-

${ }^{29}$ Jean-François Bayart, The State in Africa: The Politics of the Belly, Nueva York, Longman, 1993.

${ }_{30}$ Peter Geschiere, The Modernity of Witchcraft: Politics and the Occult in Postcolonial Africa, Charlottesville, University Press of Virginia, 1997. 
gún el Instituto Nacional de Estadística de Mozambique, 80\% de la población habla chinyanja como primera lengua, así que puede ser clasificada étnicamente como nyanja, que los académicos ubican en la familia lingüística matrilineal bantú llamada grupo maravi, pero la composición de Metangula no es homogénea. Para un significativo número de hogares, las primeras lenguas son el portugués y el chiyao (13\% y $7 \%$ respectivamente). Las adscripciones religiosas también son diversas. Más o menos la mitad de los habitantes practica el islam y la otra mitad el cristianismo. Mis datos fueron colectados durante quince meses de residencia en Metangula (febrero de 2010 a abril de 2011), además de cuatro visitas previas por periodos de dos a cuatro meses. Mi método principal puede ser caracterizado como interacción no estructurada de largo plazo u "observación participante" con la población local. ${ }^{31} \mathrm{Mi}$ emulación e integración a la vida de la comunidad ajustó mis sentidos e intelecto a las experiencias cotidianas y me expuso a una diversidad de situaciones novedosas. Tales experiencias de vida informaron $\mathrm{mi}$ investigación y me ayudaron a desarrollar afinidad, por lo que mi estudio pudo realizarse con éxito.

Reuní los datos en conversaciones personales y con pequeños grupos. Visité regularmente los hogares de veinte individuos y platiqué con ellos, sus familias y sus visitantes. Las conversaciones duraron de unos cuantos minutos hasta varias horas. Los veinte individuos seleccionados estaban entre los que amablemente me invitaron a sus casas, y los elegí sobre la base de su cordialidad y disposición a contestar mis preguntas, su franqueza al abordar temas sensibles y el esmero y minuciosidad de sus respuestas. Al seleccionarlos, cuidé que representaran los diversos estratos de la población en términos de género, edad, posición socioeconómica, educación y religión. Me basé en sus ideas y opiniones al conversar con otras personas de la comunidad a fin de confirmar mis hallazgos. Los datos que presento fueron corroborados consistentemente en esos encuentros, por lo que creo que representan al pueblo de Metangula en su conjunto. Aunque los informantes sostuvieron algunas ideas y opiniones

${ }^{31} \mathrm{H}$. Russell Bernard, Research Methods in Anthropology: Qualitative and Quantitative Approaches, Lanham, AltaMira Press, 2011. 
propias, éstas fueron más complementarias que divergentes y no percibí interpretaciones demográficamente específicas.

Como en muchos pueblos y ciudades africanas, los chismes sobre brujería y hechicería abundaron en mi estancia. Aunque los sucesos y las conductas inexplicables eran atribuidos a veces a la "suerte" o a "Dios", la "hechicería" (mfiti) y la menos malévola "medicina" (dawa) solían salir a colación como explicaciones alternativas. Por ejemplo, la enfermedad era seguramente el efecto de los celos del vecino, un marido resultaba infiel porque una mujer había puesto un polvo especial en su té, y un niño se portaba mal porque su abuela lo había iniciado en lo oculto. Aunque los señalamientos directos de hechicería y sus secuelas eran inusuales, la gente se esforzaba por desvincularse de las malas artes. Esto incluía mantener relaciones amistosas en la familia y con los vecinos, ayudar a los necesitados cuando es posible, asistir a los funerales de vecinos (un hechicero no sentiría pesar y no podría llorar) y evitar la acumulación notoria e inequitativa de riqueza material.

El desarrollo y el mantenimiento de la identidad humana también son adquiridos mediante la abstención de actos que puedan ser percibidos como antropófagos. Igual que los malauíes de la orilla occidental del lago, los residentes de Metangula describen a los hechiceros como ávidos consumidores físicos de carne humana. En varias ocasiones se me dijo que un hechicero ansioso de semejante comestible mataba a su víctima y esperaba a que su funeral terminara para desenterrar su cuerpo y devorarlo. Otros informantes me dijeron que a veces algunos entierran medicinas con el muerto para evitar que algún hechicero encuentre la tumba, o que la resguardan los días inmediatamente posteriores al funeral, cuando es más probable que el cuerpo sea desenterrado para ser comido. Cuando expresé dudas de que los hechiceros comieran realmente carne humana, varios informantes dijeron haber visto un video que lo confirmaba. Para mi sorpresa, una mujer me llevó a casa de su vecina a ver el DVD.

El disco era un video musical de Moses Makawa de 2010.32 Este artista es conocido por cantar sobre males sociales. El DVD

${ }^{32}$ Moses Makawa, Khuzumule (DvD), Lilongwe, RHEM Records, 2010, vol. 2. 


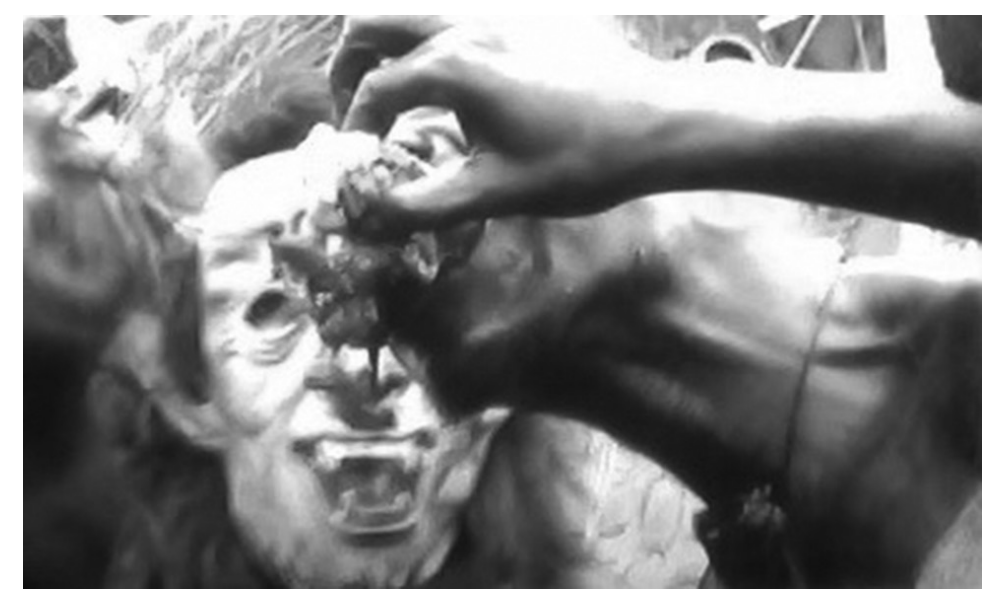

FIGURA 1.

Captura de pantalla del video musical "Umakwiya Chani”.

contiene canciones sobre violencia doméstica, corrupción de ministros religiosos y mezquindad. La mujer me mostró el video "Umakwiya Chani" (“¿Por qué estás tan enojado?"). Empieza con un hombre fumando mariguana en un portal (la mariguana es asociada a la hechicería). Las dos mujeres que me mostraron el video apuntaron a la pantalla y exclamaron: “¡Ése es el hechicero!”. El personaje salta entonces del portal y se transforma en "hechicero" renegrido y grotesco. La escena cambia a una reunión de hombres y niños, igualmente renegridos, en torno de un cesto ensangrentado con un trozo de carne adentro (figura 1). Las mujeres exclamaron: “¿Ves? ¡Están comiendo carne cruda, están comiendo humanos!”. Varios hombres aparecen con trozos de carne cruda en sus bocas y otro sonríe mostrando sus dientes sangrientos. La letra de la canción advierte que la hechicería es común y peligrosa. Cuando la canción terminó, pregunté a las mujeres cómo se las había arreglado el camarógrafo para localizar a los hechiceros y que se le permitiera filmar su nefasta actividad. “¿Cómo podemos saberlo?”, respondieron. Otros informantes con quienes discutí el DVD dijeron que éste era sólo "un ejemplo", que no representaba a hechiceros reales, pero coincidieron en que Makawa 
los describía fielmente. Se afirma que los hechiceros suelen reunirse en festines de carne humana, en los que alimentan a niños inocentes.

"La carne humana sabe dulce", me dijeron los informantes en varias ocasiones, así que quienes la consumen pueden encontrarla agradable; de hecho, su sabor es tan disfrutable que una vez que una persona la degusta desarrolla un apetito insaciable y acude a los hechiceros para obtener más, hasta convertirse con el tiempo en uno de ellos para conseguirla y compartirla en aquelarres. Así es como los hechiceros refuerzan sus filas y aseguran su abasto constante, y tal es la razón de que reclutar niños (que no conocen nada mejor que comer carne extraña) sea tan importante. Las expectativas sensoriales positivas articuladas por mis informantes sugieren que la antropofagia es localmente considerada repulsiva por razones distintas a la repugnancia innata de consumir carne humana. Es grotesca por su indiferencia hacia los semejantes. Esto sugiere que, pese a la universalidad del tabú de carne humana, la aversión a deglutirla es una experiencia corporal altamente contextualizada.

Las imágenes del video de Makawa también sirven para considerar la posición de los hechiceros en los borrosos contornos de lo humano. El hechicero no es lo opuesto a lo humano; por ejemplo, brujos y hechiceros participan en actividades socialmente orientadas, igual que los humanos: se reúnen y reparten entre ellos carne en vez de acapararla. En lo que se apartan de la humanidad es en la priorización de ellos mismos sobre los otros. Su "antisocialidad" no es sinónimo de vida reclusa sino de valoración de las relaciones como recursos de acceso privado (carne humana, en este caso) y de inmisericordia hacia el sufrimiento de los otros. Los hechiceros ejemplifican sentimientos humanos antisociales muy conocidos, como la envidia, los celos, el rencor, el resentimiento, el desprecio y el egoísmo. Estas inclinaciones, igual que el consumo de carne humana, pueden ser muy gratificantes personalmente, pero al mismo tiempo son destructivas y, por lo tanto, grotescas. Lo humano se refiere a controlar o reprimir tales propensiones (o al menos a aparentarlo) en bien de la colaboración, la porosidad, la simpatía y la vida social, la mayoría de las veces. Esto hace del proyecto de ser y devenir humano un acto constante. Hay, por lo tanto, la 
necesidad de crear y mantener continuamente a la persona en la conducta cotidiana.

El deseo de marcar distancia personal de la hechicería y la asociación de ésta con el consumo de carne humana parecen haberse aliado en Metangula en un conjunto de tabús que prohíben no sólo la antropofagia, sino también la carne de cualquier animal semejante a humanos. Comer esos animales e incluso manifestar afecto por ellos es objeto de sospecha, pues sugiere alineación con lo oculto y así también antisocialidad e inhumanidad. Los animales localmente figurados como incomodamente parecidos a los humanos incluyen no sólo la fisonomía obvia del mono, sino también serpientes, perros, gatos, leones, leopardos, hipopótamos, cocodrilos y pollos muertos sin intervención de la mano humana. La lista no es exhaustiva, sólo incluye a los animales más mencionados por los informantes como no comestibles u osati nyama (no carne). Cada una de estas especies tiene una historia documentada como comida no prohibida en la región, mas no por razones de simpatía con la antropofagia, hasta donde he podido saber. Esto sugiere que aunque estos tabús han sido probablemente heredados de generaciones anteriores, la emergencia histórica de sus connotaciones antropófagas requiere mayor atención académica. Consideremos la semejanza humana de cada animal.

Al preguntar si consumirían carne de las dos especies de monos locales, babuino ( $n k b$ wele) y mono vervet (pusi), mis informantes respondieron invariablemente que no; algunos añadieron que varios grupos étnicos vecinos sí lo hacen y que la carne de ambos primates sabe bien. Al insistir en preguntar por qué no los consumían, la respuesta más común fue que por su semejanza a la forma humana. "La mano del mono y la del humano son casi iguales", murmuró una mujer. Otra preguntó: “No es persona el babuino?". Varios informantes adujeron el origen común de monos y humanos para justificar su aversión a comerlos. En una interpretación inversa de la teoría de la evolución, todos los primates descienden de un ancestro común humano, y su transformación es un castigo de Dios. Pero en Metangula, como en muchas poblaciones africanas, ser humano es algo más que tener forma humana física; también es asunto de comportamiento. Muchos informantes subrayaron 
su aversión a consumir primates tras describir la conducta, similar a la humana, de éstos; por ejemplo cuando los babuinos prueban las raíces de mandioca para comprobar si son amargas, o cuando escarban los montecillos de camote para determinar si las raíces están maduras para consumirlas. Una mujer me contó sobre un babuino hembra bebé que encontró y crió como niña. La mona acudía al ser llamada por su nombre, bebía té en tasa y se sentaba con los humanos cuando conversaban, "igual que una persona”, insistía la mujer. Sus hijas recordaron que ella lloró durante días cuando la mona murió. Varios informantes indicaron que los babuinos, a veces, tienen relaciones sexuales con mujeres a la fuerza. Todos estos detalles subrayan la semejanza entre humanos y primates en forma y conducta.

La única otra referencia de semejanza física de animales y humanos que registré como causa de prohibición de comer su carne en Metangula fue la de los pollos muertos de muerte natural. Para justificar su aversión, algunos citaron principios islámicos, pero la mayoría la justificó o interpretó los principios islámicos a partir del aspecto de la carne, similar a la de las personas enfermas; la rigidez corporal del pollo también es asimilada a la del cuerpo humano recién muerto. Estas ideas de antropofagia, quizá de la vida perdida en sentido más amplio, eran inapetentes. Y proyectar una imagen propia, confortable, con el consumo de carne semejante a la de un cadáver habría sido tal vez peligroso. Aun así, algunas personas comen en privado animales muertos de muerte natural. Cuando advertí por tercera vez que mis anfitriones comían pollo furtivamente sin haberme ofrecido, ingenuamente pregunté por qué. Apenada por haberme ofendido sin proponérselo, la señora de la casa me explicó las buenas intenciones de su discriminación: "No quise ofenderla sirviéndole la carne de un pollo muerto del mal de Newcastle (chu'ule) y pensamos que usted no debería comerla". Metangula atravesaba entonces por un brote de ese virus, que había matado muchos pollos. Con tantos pollos perdidos, la gente parecía más dispuesta a comer carne tiesa que en otras circunstancias. Varios informantes manifestaron que vigilaban celosamente a sus pollos enfermos y los sacrificaban justo antes de que murieran para garantizar que la carne podía ser comida. 
Otras especies tabú son consideradas como semejantes a humanos, mas no por su forma física. Por ejemplo, los informantes me explicaron la prohibición de comer carne de perro y de víbora por sus sentimientos similares a los humanos. La protección canina de los humanos y la abstención ocasional de la víbora a atacarlos son demostraciones de compasión similar a la humana. Una mujer fue más allá al afirmar que las víboras son capaces de encontrar y administrar curas a víboras heridas, con lo que muestran compasión interespecie, pero no encontré evidencia al respecto. Algunos informantes enlistaron a las mascotas domésticas, perros y gatos, como no comestibles por su propensión a buscar compañía, como los humanos. Igual que las relaciones humanas, las relaciones de perros y gatos con la gente son recíprocas e interdependientes: los perros dan protección y los gatos matan ratas a cambio de ser cuidados por humanos. Matar y comer semejantes "amigos" (como mis informantes los llamaban sólo en conversaciones sobre ingestión de carne), si bien no es comparable a comer carne humana, es considerado impropio sobre la base de su incorporación a la vida social. Esto también habla de la construcción de humanidad mediante acciones y sentimientos.

El consumo de especies que atacan, muerden o comen humanos es más parecido a la antropofagia propiamente dicha. La lista incluye leones, leopardos, hipopótamos, cocodrilos y víboras. Consumirlos, dijeron varios informantes, es como comer al humano incorporado en ellos. Algunos animales pueden incorporar carne y energía humanas, pero otros tienen el potencial de encarnar espíritus humanos. Según mis informantes, como ha sido reportado en toda África, los hechiceros y otras personas poderosas pueden transformarse en animales depredadores, particularmente en leones. ${ }^{33}$ La metamorfosis, según se me explicó en Metangula, ocurre de dos maneras. La primera es por influjo de medicinas obtenidas por un sanador tradicional a partir de gusanos de vómito, los cuales, con el debido cuidado, pueden crecer y llegar a ser leones. Un hombre me contó, basado en su experiencia personal, que una familia po-

${ }^{33}$ Elizabeth Isichei, Voices of the Poor in Africa, Rochester, University of Rochester Press, 2002. 
día escuchar rasguños en la puerta después de un funeral, salir a ver y no encontrar nada. Si deseaban criar al humano-león, debían dejar un plato con comida en el porche para alimentarlo. Con el debido cuidado, el animal crecía en tamaño y vitalidad. El segundo método para volverse león después de la muerte es la transformación física. Los reportes de tal prodigio son considerados inusuales en la época contemporánea, pero en enero de 2011 se esparció el rumor de que un anciano muerto se había convertido en león. A su muerte, su cabeza creció y en su piel comenzó a crecer una fina capa de pelaje. A fines del mismo mes hablé con sus deudos, quienes me confirmaron la descripción y me dijeron que no se habían quedado sentados a esperar la transición del muerto, que primero le cortaron el cuello, luego le cercenaron la cabeza y le abrieron el pecho para extraerle el corazón. Al ver que los síntomas continuaban, le extirparon los intestinos y finalmente el pene. En este punto, el león "cesó de respirar" y el cuerpo fue sepultado apresuradamente. Los familiares explicaron que la medicina que el hombre había ingerido era poderosa, lo que requirió tomar medidas extremas. Medicinas menos poderosas pueden ser neutralizadas mediante la inyección de aceite caliente en los oídos del difunto. Éste emite entonces un chillido como de cerdo, indicio de que la transformación habría sido conjurada.

No reporto estos incidentes para sugerir que la gente con la que trabajé es salvaje o extraña sino para mostrar que los discursos humano-león, además de servir como metáforas del poder y su acumulación, tienen implicaciones de conducta humana; ${ }^{34}$ asimismo, para la antropofagia. El concepto de transfiguración también sirve para ilustrar los contornos borrosos de lo humano. La distinción ontológica entre animales y humanos no es tajante: compartimos atributos de socialidad, conciencia y acciones subjetivas, y los pueblos maravi son notables por su empatía con los animales, especialmente con los mamíferos debido al reconocimiento de tales "afinidades fundamentales". ${ }^{35}$ Pero los animales no son personas ni humanos y, como los hechiceros, sirven como álter ego de lo humano. Los animales

\footnotetext{
${ }^{34}$ Harry G. West, Kupilikula: Governance and the Invisible Realm in Mozambique, Chicago, University of Chicago Press, 2005.

${ }^{35}$ Brian Morris, Animals and Ancestors: An Ethnography, Nueva York, Berg, 2000.
} 
también se asemejan a los hechiceros (o a la inversa) en que se mueven por la noche, no usan ropa, consumen carne cruda y carecen de previsión para subsistir de recursos cultivados más allá de la fuerza bruta.

La conexión entre esos animales en que los humanos pueden convertirse y los animales tabú es realzada por el ejemplo de la carne de hipopótamo. En el pasado el hipopótamo era comida prohibida. Esto fue cuando se creía que los leprosos se convertían en hipopótamos a su muerte. La enfermedad ha sido desde entonces casi erradicada en el área, y en el momento de la investigación el hipopótamo se reportó como una fuente aceptable de comida. Nunca vi a nadie comer su carne, así que no puedo aportar información de primera mano sobre su aptitud. Tampoco registré ningún caso de su ingesta en la encuesta de un año sobre el consumo alimenticio que diseñé y supervisé mientras estuve en Metangula. Pero un día que un hipopótamo muerto e hinchado encalló en la bahía, vi a más de cien sujetos blandiendo cuchillos y machetes con el propósito de obtener un trozo de él (figura 2). No era gente hambrienta sino gente común dispuesta a aprovechar la oportunidad. Al final nadie comió hipopótamo, pues el alcalde y la autoridad del distrito dictaminaron que el animal posiblemente había muerto de enfermedad y, para decepción de la turba, ordenaron confinar el cadáver para incinerarlo a las afueras del pueblo. Sin embargo, que la gente haya estado deseosa de obtener una porción sugiere que el tabú del hipopótamo es cosa del pasado.

Además de presentar evidencia de que los tabús de consumo de carne pueden relacionarse con la constitución del animal percibida como antropomórfica, el ejemplo de la relación hipopótamo-leproso sugiere que los tabús de alimentos no son productos inveterados de la tradición, ni han sido inconscientemente repetidos a lo largo del tiempo. Más que apelar a la "tradición" como justificación única de los tabús, deberíamos considerar que éstos satisfacen necesidades de creyentes contemporáneos. Las prácticas culturales dependen de su contexto, son históricamente emergentes y son sometidas a reinterpretación constante para satisfacer necesidades presentes. En otras palabras, las angustias cambian; igual, las prohibiciones culturales. Por esta razón, no debería sorprender que el tabú de 


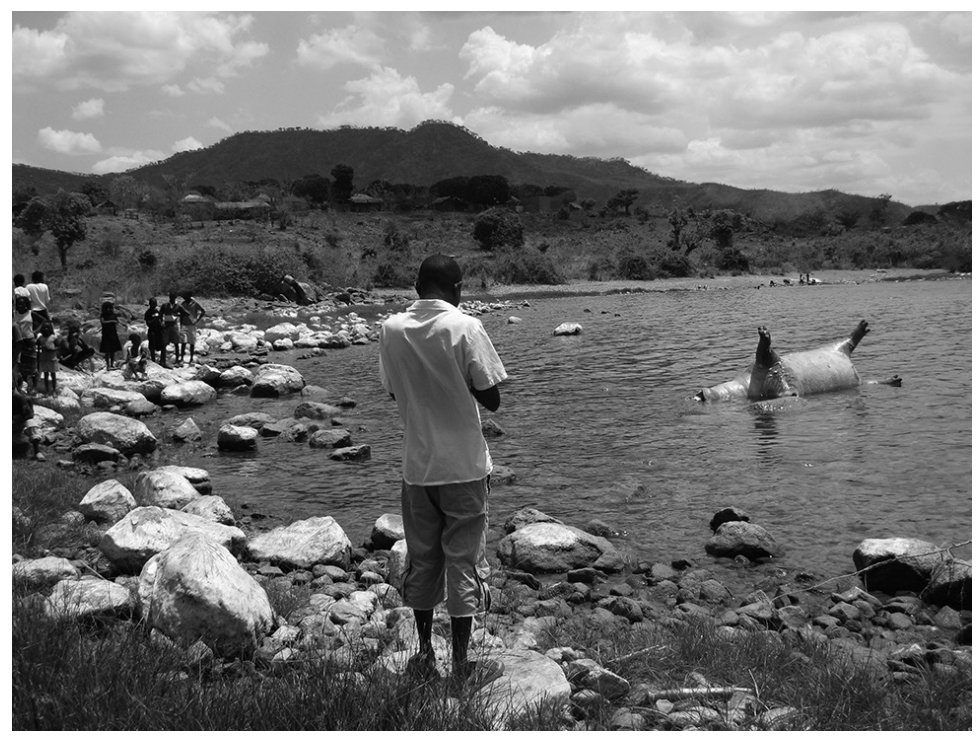

Figura 2. Curiosos observan a un hipopótamo muerto (foto de Arianna Huhn).

consumir pollos muertos de muerte natural se torne laxo si las circunstancias determinan la inconveniencia de desperdiciar su proteína. La gente hace cosas con las prohibiciones de alimentos, no siempre las sigue por rutina.

La incómoda semejanza entre humanos y varios animales como base de los tabús alimentarios es una réplica del lenguaje usado por mis informantes. Pero la sugerencia de que el discurso sobre la abstención de esos alimentos y de consumir animales semejantes a humanos tiene el efecto de confirmar el desinterés de los creyentes en alimentarse de otros humanos y marcar su distancia de lo oculto es mi interpretación personal. Cuando traté de obtener respuestas más elaboradas de los nativos sobre aversiones a la carne se me respondió simplemente: "Es lo que nuestros ancestros hacían". Otros informantes dieron bases teológicas a su razonamiento, al argüir que desde hace mucho Dios dividió los alimentos entre los pueblos de la Tierra, y que la dieta actual es simplemente lo que se les dio (o no se les dio) a los nyanja para comer. Algunos informantes musulmanes añadie- 
ron que el cocodrilo y el hipopótamo son físicamente imposibles de matar porque no pueden ser muertos de un solo tajo en el cuello, de acuerdo con las prescripciones halal. El credo islámico también impone prohibiciones al consumo de animales muertos de muerte natural. Sin embargo, Ian Dicks encontró evidencia lingüística y cultural de tabús maravi muy similares a los de halal anteriores a la difusión del islam en la región. ${ }^{36}$ Es interesante también que mis informantes sólo refirieran la aversión a pollos muertos sin intervención humana, no a otros animales de corral (como vacas y cabras) y, entre estos animales, es sólo la carne de pollo la que se asemeja a la humana en color y consistencia.

Cualesquiera que sean las razones, los informantes reconocieron la especificidad local de sus tabús; en otras palabras, comer monos, víboras, perros, gatos, leones, leopardos, hipopótamos y cocodrilos es tabú sólo para la gente de Metangula. Las personas de otras comunidades pueden comerlos y de hecho lo hacen sin ser acusados de antropofagia o de inclinaciones ocultistas. Este escenario podría sugerir la existencia de un estatus totémico para esos animales, pero yo no registré evidencia de su uso emblemático en la comunidad ni escuché hablar sobre mitos totémicos por los cuales la gente alegara descendencia de animales. Al demandar adhesión a las prohibiciones de comida sólo a los habitantes de Metangula, la creencia en los tabús devino señal expedita de identificación con la comunidad. Su desobediencia hace inmediatamente reconocible al individuo como forastero y extraño. El estatus de extraño es normal en viajeros o visitantes, pero que un residente permanezca intencionalmente apartado e indiferente a la comunidad es causa suficiente para cuestionar su humanidad. En la práctica, entonces, los tabús alimentarios en Metangula reflejan y refuerzan la significancia social de las interrelaciones, justo como sostengo que lo hacen en forma. No pretendo insinuar que ésta sea la única razón que explica todos los tabús alimentarios en Metangula, o que éstos surgieron para servir a ese fin en particular. Hay evidencia robusta de que otros animales (como los camaleones) son tabú

${ }^{36}$ Ian Dicks, An African Worldview: The Muslim Amacinga Yawo of Southern Malawi, Zomba, Kachere Series, 2012. 
por su asociación con el mundo espiritual. Lo importante es que la semejanza de los animales a los humanos, y así su consumo a la antropofagia, es el lenguaje y la razón que mis informantes usaron para describir sus prohibiciones, lo que sugiere que los valores de socialidad, porosidad y circulación no sólo están implantados en los tabús, sino que además son íntimamente representados y encarnados a través de ellos.

\section{Conclusión}

Este artículo ha afirmado que la lucha por crear y sostener una disposición compasiva y prosocial, y así una identidad social como persona humana en oposición a la de hechicero, se manifiesta en los tabús alimentarios en un pueblo africano. Específicamente, la gente de Metangula cultiva y evita escrúpulos sobre la orientación prosocial, en parte mediante la abstención de consumir ciertas carnes similares a la humana. Entre estos animales figuran mamíferos, reptiles y aves. El cuerpo humano, por lo tanto, no basta para afirmar lo humano del consumidor y lo consumido. Además de concretar una cuestión fundamental desatendida en las discusiones académicas sobre antropofagia - por qué no comer gente-, este artículo ha puesto en claro que la consideración de la subjetividad individual y la intencionalidad en la adhesión a los tabús alimentarios nos puede ayudar a entender tales acciones como satisfactorias de necesidades de creyentes contemporáneos, más que productos de la tradición sempiterna, mediante los cuales el yo no sólo se expresa, sino que además se constituye, y la socialidad se representa y encarna. ${ }^{37} \mathrm{La}$ información también sugiere que la reacción de disgusto visceral ante la posibilidad de digerir humanos no es universal. En Metangula, la carne humana es tenida como de buen sabor. La antropofagia es despreciada, escarnecida y tachada como repugnante porque es un acto nefario de lo oculto. La antropofagia representa el triunfo y la priorización de

${ }^{37}$ Helen Macbeth, Wulf Schiefenhövel y Paul Collison, "Cannibalism: No Myth, but why so Rare?”, en Jeremy MacClancy, C. J. K. Henry y Helen M. Macbeth (coords.), Consuming the Inedible: Neglected Dimensions of Food Choice, Nueva York, Berghahn Books, 2007, pp. 189-203. 
lo antisocial sobre la compasión, lo que constituye una afrenta a la comunidad y al yo individual, cuya existencia metafísica depende de la circulación y la interdependencia. El tabú del canibalismo es significativo como una de las pocas costumbres verdaderamente universales (lo que sugiere que tiene bases biológicas), pero es claro también que la construcción del disgusto tiene mucha especificidad cultural.

Los ejemplos expuestos en este artículo, en los que el consumo de carne no humana es visto como antropofagia, no son inauditos por la holgura de interpretaciones que admiten. Los tabús alimentarios compasivos son comunes, diversos e incluyen proscripciones basadas en el color, la textura, el comportamiento y la lingüística. ${ }^{38}$ Aparte de los animales totémicos, los primates y el caso de los dobuanos de Melanesia, que asimilan el camote a la carne humana porque su raíz y su cuerpo están "sepultados" bajo montículos inmundos, he encontrado pocos casos de consumo de alimentos que sean descritos compasivamente por nativos (emic) como antropófagos. ${ }^{39}$ Marshall Sahlins hace una interpretación simbólica externa (etic) de la conveniencia y valoración de los cortes de carne en Estados Unidos como inversamente relacionados con la integración del animal a la sociedad y así con su cercanía a los humanos. ${ }^{40}$ En combinación con la preferencia por la carne sobre los órganos (la primera representando al cuerpo y los segundos al "yo" interno), Sahlins concluye que el consumo de carne en Estados Unidos es impelido por una prohibición implícita del canibalismo.

Los tabús creados para alejar a los individuos de cosas percibidas como partes de ellos mismos son comunes. Los ejemplos más patentes son los de incesto y otras reglas de exogamia. Chris Knight presenta varios casos de las islas Trobriand y Australia, donde la palabra "tabú" se traduce como "carne", lo que lingüísticamente indica que los objetos prohibidos están vinculados a la persona. "El punto crucial —sostiene Knight- es que

${ }^{38}$ Simoons, Eat not this Flesh, op. cit., pp. 173-176, 309.

${ }^{39}$ Maurice Bloch y Jonathan Parry, "Introduction”, en Maurice Bloch y Jonathan Parry (coords.), Death and the Regeneration of Life, Cambridge, Cambridge University Press, 1982, p. 28.

${ }^{40}$ Marshall Sahlins, Culture and Practical Reason, Chicago, University of Chicago Press, 1978. 
el 'yo', como quiera que se le conciba, no es apropiado por el yo. Es para el disfrute de otros". ${ }^{41}$ Uno podría extraer la conclusión general de que las propensiones comunales e individuales están íntimamente ligadas, lo que convierte a la antropofagia en un acto especialmente poderoso, donde la obtención de la carne requiere contrariar la fuerza de la vida y debilitar la estabilidad de familias y comunidades por apetencias personales. Peggy Reeves Sanday describe la antropofagia como cargada de símbolos, precisamente, por estas razones, y subraya que los tabús sirven como esfuerzos de control de las fuerzas vitales consideradas necesarias para la reproducción física (personal) y social. $^{42}$

He planteado en este artículo que, en Metangula, los tabús alimentarios son espacios donde los individuos negocian el dilema de balancear la porosidad y el aislamiento. La primera es necesaria para acceder a las gratificaciones y posibilidades que surgen de la solidaridad y la cohesión de grupo, mientras que el segundo posibilita poder y recursos (incluidas las carnes apetitosas) que son atractivos pero difíciles de acumular y gozar sin dañar u obstruir a otros. Colocarse uno mismo entre los extremos de socialización y antisocialización es un dilema existencial universal o una parte de lo humano. Lo concebido como humano entre varias posibilidades cambia de una población a otra. En Metangula, la persona debe ser construida activamente mediante conductas que muestren la valoración positiva del yo en la sociedad, no al margen de ella. Este requerimiento se ha extendido aparentemente a los tabús que prohíben el consumo de animales semejantes a humanos como una forma de pseudoantropofagia, para que el individuo tome distancia de lo oculto. Al incluir en la construcción de lo apropiadamente humano la abstención de comer carne humana y carne semejante a la humana, la gente de Metangula responde la cuestión de qué es lo humano, como lo es, con lo que es humano.

\section{Traducción del inglés: Ramón Cota Meza}

\footnotetext{
${ }^{41}$ Chris Knight, Blood Relations: Menstruation and the Origins of Culture, New Haven, Yale University Press, 1995, p. 8.

${ }^{42}$ Peggy Reeves Sanday, Divine Hunger: Cannibalism as a Cultural System, Cambridge, Cambridge University Press, 1986.
} 
Dirección institucional de la autora:

Department of Antbropology

California State University, San Bernardino

5500 University Parkway, Room SB-327

San Bernardino, $C A$

92407-2397, USA

abubn@csusb.edu

\section{Bibliografía}

Arens, W., The Man-Eating Myth: Anthropology \& Anthropophagy, Nueva York, Oxford University Press, 1979.

BAYART, Jean-François, The State in Africa: The Politics of the Belly, Nueva York, Longman, 1993.

Beidelman, T. O., Moral Imagination in Kaguru Modes of Thought, Washington, Smithsonian Institution Press, 1993.

Bernard, H. Russell, Research Methods in Anthropology: Qualitative and Quantitative Approaches, Lanham, AltaMira Press, 2011.

BLOCH, Maurice y Jonathan Parry, "Introduction”, en Maurice Bloch y Jonathan Parry (coords.), Death and the Regeneration of Life, Cambridge, Cambridge University Press, 1982, pp. 1-44.

Comaroff, John y Jean Comaroff, "On Personhood: An Anthropological Perspective from Africa”, Social Identities, año 7, núm. 2, 2001, pp. 267-283.

Dicks, Ian, An African Worldview: The Muslim Amacinga Yawo of Southern Malawi, Zomba, Kachere Series, 2012.

Dietler, M., "Digesting the Feast - Good to eat, Good to drink, Good to think: An Introduction”, en Michael Dietler y Brian Hayden (coords.), Feasts: Archaeological and Ethnographic Perspectives on Food, Politics, and Power, Washington, Smithsonian Institution Press, 2001, pp. 1-22.

Douglas, Mary, Purity and Danger: An Analysis of Concepts of Pollution and Taboo, Nueva York, Praeger, 1966.

Feeley-Harnik, Gillian, "Religion and Food: An Anthropological Perspective", Journal of the American Academy of Religion, año 63, núm. 3, 1995, pp. 565-582.

Fieldhouse, Paul, Food and Nutrition: Custom and Culture, Nueva York, Chapman and Hall, 1995.

GeIssler, Wenzel y Ruth Prince, The Land is Dying: Contingency, 
Creativity and Conflict in Western Kenya, Nueva York, Berghahn Books, 2010.

Gell, Alfred, "Reflections on a Cut Finger: Taboo in the Umeda Conception of the Self", en R. H. Hook (coord.), Fantasy and Symbol: Studies in Anthropological Interpretation, Nueva York, Academic Press, 1979, pp. 133-148.

Geschiere, Peter, The Modernity of Witchcraft: Politics and the Occult in Postcolonial Africa, Charlottesville, University Press of Virginia, 1997.

Harris, Marvin, Good to Eat: Riddles of Food and Culture, Nueva York, Simon and Schuster, 1985.

HuHn, Arianna, "The Tongue only works without Worries: Sustenance and Sentiment in a Mozambican Town", Food and Foodways, año 21, núm. 3, 2013, pp. 186-210.

IsICHEI, Elizabeth, Voices of the Poor in Africa, Rochester, University of Rochester Press, 2002.

KANYIKE, Edward, The Principle of Participation in African Cosmology and Anthropology, Balaka, Montfort Media, 2004.

Karp, Ivan, "Personhood, Concepts of", en John Middleton (ed.), Encyclopedia of Africa South of the Sahara, vol. 3, Detroit, Thomson-Gale, 1997, pp. 342-346.

Kimmerle, Heinz, "Ubuntu and Communalism in African Philosophy and Art", en Henk van den Heuvel, Mzamo Mangaliso y Lisa van de Bunt (coords.), Prophecies and Protests: Ubuntu in Glocal Management, Amsterdam, Rozenburg Publishers, 2006, pp. 79-92.

KNIGHT, Chris, Blood Relations: Menstruation and the Origins of Culture, New Haven, Yale University Press, 1995.

LEwIS, I. M., Religion in Context: Cults and Charisma, Cambridge, Cambridge University Press, 1996.

Lindenbaum, Shirley, "Thinking about Cannibalism”, Annual Review of Anthropology, año 33, núm. 1, 2004, pp. 475-498.

Maсветн, Helen, Wulf Schiefenhövel y Paul Collison, "Cannibalism: No Myth, but why so Rare?”, en Jeremy MacClancy, C. J. K. Henry y Helen M. Macbeth (coords.), Consuming the Inedible: Neglected Dimensions of Food Choice, Nueva York, Berghahn Books, 2007, pp. 189-203.

MaKawa, Moses, Khuzumule (DvD), Lilongwe, RHEM Records, 2010, vol. 2.

Messer, Ellen, "Food Definitions and Boundaries: Eating Constraints and Human Identities", en Jeremy MacClancy, C. J. K. Henry y Helen M. Macbeth (coords.), Consuming the Inedible: Neglect- 
ed Dimensions of Food Choice, Nueva York, Berghahn Books, 2007, pp. 53-66.

Morris, Brian, Animals and Ancestors: An Ethnography, Nueva York, Berg, 2000.

Murray, Colin y Peter Sanders, Medicine Murder in Colonial Lesotho: The Anatomy of a Moral Crisis, Londres, Edinburgh University Press, 2005.

Osseo-Asare, Fran, Food Culture in sub-Saharan Africa, Westport, Greenwood Press, 2005.

SAHLIns, Marshall, Culture and Practical Reason, Chicago, University of Chicago Press, 1978.

SAnday, Peggy Reeves, Divine Hunger: Cannibalism as a Cultural System, Cambridge, Cambridge University Press, 1986.

SHAw, Rosalind, "The Production of Witchcraft/Witchcraft as Production: Memory, Modernity, and the Slave Trade in Sierra Leone", American Ethnologist, año 24, núm. 4, 1997, pp. 856-876.

Simoons, Frederick J., Eat not this Flesh: Food Avoidances from Prehistory to the Present, Madison, University of Wisconsin Press, 1994.

Sutton, E., "Food and the Senses", Annual Review of Antbropology, año 39, núm. 1, 2010, pp. 209-223.

Van Breugel, J. W. M., Chewa Traditional Religion, Zomba, Kachere Series, 2001.

West, Harry G., Kupilikula: Governance and the Invisible Realm in Mozambique, Chicago, University of Chicago Press, 2005.

WHITE, Luise, Speaking with Vampires: Rumor and History in Colonial Africa, Berkeley, University of California Press, 2000.

WhiteHEad, Neil L. y Robin Wright, In Darkness and Secrecy: The Anthropology of Assault Sorcery and Witchcraft in Amazonia, Durham, Duke University Press, 2004. 
